\title{
Diphenylmethoxyacetic Acid and Some Related Compounds
}

\author{
RICHARD DAHLBOM and LARS-ERIC ÖSTERBERG
}

Central Laboratories, Astra, Södertälje, Sueden

\begin{abstract}
A s starting materials for certain syntheses we required diphenylmethoxyacetic acid, diphenylmethylthioglycolic acid and the amides and ethyl esters of these acids. Among these compounds only diphenylmethylthioglycolic acid appears to have been reported in the literature ${ }^{1}$. This paper describes the syntheses of these new compounds and their properties.

Diphenylmethoxyacetic acid was prepared by treating the sodium salt of benzohydrol with chloroacetic acid.
\end{abstract}

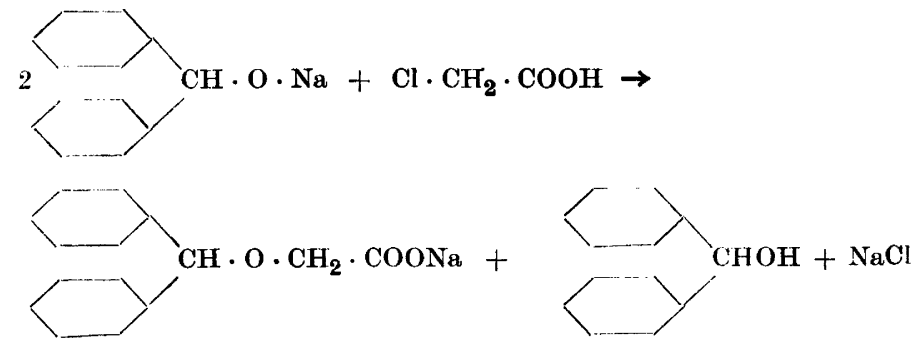

The ethyl ester could be obtained by esterification with ethanol and sulfuric acid. It was, however, prepared more conveniently from ethyl bromoacetate and the sodium salt of benzohydrol.

In attempting to obtain the amide via the acid chloride, it was found that the acid was disintegrated by treatment with chlorinating agents such as thionyl chloride, phosphorus pentachloride and phosphorus oxychloride and only benzohydrol or diphenylmethyl chloride could be isolated.

By reacting the acid with equimolar amounts of thionyl chloride and pyridine and treating the reaction product with ammonia by the method of Human and Mills ${ }^{2}$, the acid amide was certainly obtained, but it was synthesized more conveniently and with a better yield by heating the ethyl ester with alcoholic ammonia in a sealed vessel at $100^{\circ}$.

As a starting material for heterocyclic compounds, especially imidazolines, we required diphenylmethoxyacetonitrile too. It proved, however, impossible 
to obtain this compound by dehydration of the amide. Distillation with phosphorus pentoxide caused cleavage of the molecule at the ether linkage, benzohydrol being formed. Treatment with thionyl chloride or phosphorus chlorides yielded diphenylmethyl chloride. We succeded, however, in producing the desired imidazoline in another way, by the action of 2-(chloromethyl)imidazoline on the sodium salt of benzohydrol ${ }^{3}$.

Diphenylmethylthioglycolic acid was prepared by the procedure of Holmberg ${ }^{1}$. The ethyl ester was obtained by esterification with ethanol and sulfuric acid in the usual way. The amide of this acid was prepared by heating the ester with alcoholic ammonia in a sealed vessel.

In this connection it seemed to us to be worth while investigating whether the $\beta$-dialkylaminoethyl esters of these two acids possessed any interesting pharmacological properties. These compounds bear a certain structural resemblance to Trasentin (I) and Benadryl (II), which are well known as an antispasmodic and an antihistamine agent, respectively.

We therefore prepared the $\beta$-diethylaminoethyl esters of these acids (III, IV) by treating the acids with $\beta$-diethylaminoethyl chloride by the method of Miescher and Hoffmann 4 .

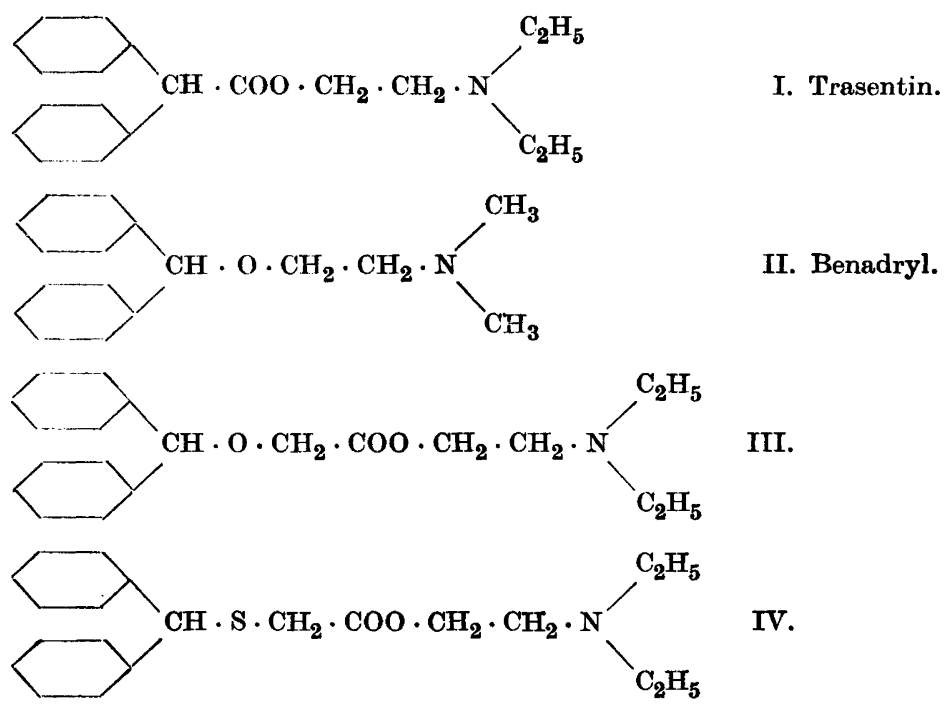

The compounds III and IV have been directly compared with Benadryl on isolated guinea-pig ileum *. They exerted a slight antihistamine action, and

* The pharmacological investigations have been carried out at Astra's Biological Department by Dr. S. Wiedling. 
their antispasmodic effect against barium chloride and acetylcholine was comparatively weak.

\title{
EXPERIMENTAL
}

\author{
Diphenylmethoxyacetic acid
}

$184 \mathrm{~g}$ of benzohydrol was dissolved in $200 \mathrm{ml}$ of dry toluene, and $23 \mathrm{~g}$ of powdered sodium added. The mixture was allowed to stand at room temperature overnight, and was then warmed with stirring for two hours at $100^{\circ}$. After cooling, a solution of $47 \mathrm{~g}$ of chloroacetic acid in $200 \mathrm{ml}$ of toluene was added in portions, and the mixture was then refluxed for 7 hours. After cooling to room temperature, the mixture was extracted with $600 \mathrm{ml}$ of $0.2 \mathrm{~N}$ sodium hydroxide. The alkaline solution was acidified with $5 \mathrm{~N}$ hydrochloric acid, whereupon the crude acid separated as an oil, which crystallized in a couple of days. The yield was $76 \mathrm{~g}$. Extraction of the acidified solution with ether and evaporation of the ether yielded another $1.5 \mathrm{~g}$ of the acid. The total yield amounted to $64 \%$. From the toluene $85 \mathrm{~g}$ of benzohydrol could be recovered.

The crude acid was recrystallized from $50 \%$ ethanol. M. p. 74-75'.

$$
\begin{array}{llllllll}
\mathrm{C}_{15} \mathrm{H}_{14} \mathrm{O}_{3}(242.3) & \text { Calc. } & \text { C } & 74.5 & \text { H } & 5.78 & \text { Eq. wt. } 242 \\
& \text { Found } & \text { " } & 75.0 & \text { " } & 5.67 & & 242
\end{array}
$$

For characterizing of the acid, its phenacyl ester was prepared.

A mixture of $3.1 \mathrm{~g}$ of the acid, $2.0 \mathrm{~g}$ of phenacyl bromide, $0.5 \mathrm{~g}$ of sodium carbonate and $30 \mathrm{ml}$ of $66 \%$ ethanol was refluxed for 1 hour. The mixture was then poured out into ice water, whereupon the ester separated as an oil, which soon crystallized. After recrystallization from ethanol it melted at $92-94^{\circ}$.

$$
\begin{array}{llll}
\mathrm{C}_{23} \mathrm{H}_{20} \mathrm{O}_{4}(360.4) & \text { Calc. } & \text { C } 76.7 & \text { H } 5.58 \\
& \text { Found } & 76.7 & 5.60
\end{array}
$$

Ethyldiphenylmethoxyacetate

A solution of the sodium salt of benzohydrol was prepared from $50 \mathrm{~g}$ of benzohydrol, $5.75 \mathrm{~g}$ of sodium and $225 \mathrm{ml}$ of toluene along the lines of the preceding experiment. $42 \mathrm{~g}$ of ethyl bromoacetate was added, and the mixture was refluxed for 7 hours. After cooling, the mixture was washed with water in order to remove the separated sodium bromide. The toluene layer was dried over calcium chloride, and the toluene was distilled off on a water bath at $15 \mathrm{~mm}$. The residue, $72 \mathrm{~g}$, was distilled in high vacuum. The fraction boiling at $105-115^{\circ}$ bath temperature at $0.002 \mathrm{~mm}$ was collected. Yield $30.0 \mathrm{~g}$ (41 \%) of a colourless oil.

$$
\begin{array}{lllll}
\mathrm{C}_{17} \mathrm{H}_{18} \mathrm{O}_{3}(270.3) & \text { Calc. } & \text { C } 75.6 & \text { H } 6.71 \\
& \text { Found } & \text { " } 76.0 & & 6.70
\end{array}
$$

This ester was very sensitive to alkaline hydrolysis. Thus it was saponified almost instantaneously at room temperature by means of ethanolic sodium hydroxide. 
$7.5 \mathrm{~g}$ of the ethyl ester was dissolved in $7.5 \mathrm{ml}$ of ethanol, and $1.9 \mathrm{~g}$ of sodium hydroxide dissolved in $30 \mathrm{ml}$ of ethanol was added. A vigorous reaction took place, and in a couple of minutes the solution had solidified. The precipitate was filtered off, dissolved in $\mathbf{2 0 0}$ $\mathrm{ml}$ of water and acidified with $2 \mathrm{~N}$ hydrochloric acid, whereupon $4.0 \mathrm{~g}$ of white crystals separated. After recrystallization from $50 \%$ ethanol, m. p. $74-75^{\circ}$ and eq. wt. 242.

$$
\text { Diphenylmethoxyacetamide }
$$

A. It proved advantageous to prepare this compound from the crude ethyl ester and not from the distilled product. $75.0 \mathrm{~g}$ of the crude ester, prepared as described above, was dissolved in $115 \mathrm{ml}$ of ethanol, and the solution was saturated with dry ammonia gas in the cold. The mixture was heated in a sealed steel tube at $100^{\circ}$ for sixteen hours. On cooling, $31 \mathrm{~g}$ of white crystals separated. The yield was $47 \%$ calculated upon benzohydrol. The amide was recrystallized from $66 \%$ ethanol. M. p. 134-135 .

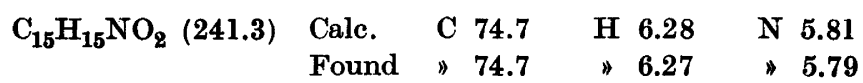

B. To a solution of $7.3 \mathrm{~g}$ of diphenylmethoxyacetic acid and $2.4 \mathrm{~g}$ of pyridine in 75 $\mathrm{ml}$ of ether, $3.58 \mathrm{~g}$ of thionyl chloride was added, drop-wise with stirring. The mixture was left at room temperature for an hour, $75 \mathrm{ml}$ of pyridine was then added, and the mixture was saturated with dry ammonia gas and was allowed to stand overnight. The mixture was then poured out into ice water, and the precipitate was collected. Yield $3.1 \mathrm{~g}(42 \%)$. After recrystallization from $66 \%$ ethanol m.p. 134-135 .

$$
\beta \text {-Diethylaminoethyl diphenylmethoxyacetate }
$$

$12.1 \mathrm{~g}$ of diphenylmethoxyacetic acid, $8.6 \mathrm{~g}$ of $\beta$-diethylaminoethyl chloride hydro. chloride ${ }^{5}$ and $13.5 \mathrm{~g}$ of dried potassium carbonate were suspended in $50 \mathrm{ml}$ of acetone and refluxed with stirring for 24 hours. The mixture was filtered, and the chilled filtrate acidified with a solution of dry hydrogen chloride in acetone. The resulting precipitate was collected, the yield was $6.7 \mathrm{~g}$. After recrystallization from ethyl acetate the pure hydrochloride melted at $143-144^{\circ}$.

$$
\begin{array}{llll}
\mathrm{C}_{21} \mathrm{H}_{27} \mathrm{NO}_{3} \cdot \mathrm{HCl}(377.9) & \text { Calc. } & \text { Cl } 9.39 & \mathrm{~N} 3.70 \\
& \text { Found } & 9.31 & \text { " } 3.65
\end{array}
$$

The free base could be obtained by dissolving the hydrochloride in water and precipitating with sodium carbonate solution. This yielded an oil, which was extracted with ether. The ether was died over calcium chloride and distilled off. The residue distilled at $0.002 \mathrm{~mm}$ at $160^{\circ}$ in the bath giving a colourless oil.

$$
\begin{gathered}
\mathrm{C}_{21} \mathrm{H}_{27} \mathrm{NO}_{3} \text { (341.4) Calc. } \mathrm{N} 4.12 \text { Found } \mathrm{N} 4.11 \\
\text { Diphenylmethylthioglycolic acid }
\end{gathered}
$$

Holmberg ${ }^{1}$ prepared this compound by heating equivalent parts of benzohydrol and thioglycolic acid for 4 hours on the water bath either suspended in $2 N$ hydrochloric acid or without any diluent. We prepared it by a slight modification of the latter method. 
If a drop of conc. hydrochloric acid was added to the reaction mixture, a vigorous reaction commenced, and in a few minutes the crude acid crystallized.

$$
\text { Ethyldiphenylmethylthioglycolate }
$$

A mixture of $5.0 \mathrm{~g}$ of diphenylmethylthioglycolic acid, $5 \mathrm{ml}$ of conc. sulfuric acid and $50 \mathrm{ml}$ of ethanol was refluxed for 5 hours. The solution was poured out into $300 \mathrm{ml}$ of ice water, and the crude ester was then extracted with ether. The ether layer was washed with sodium carbonate solution and water, dried over calcium chloride and evaporated. Distillation of the residue at $0.001 \mathrm{~mm}$ at $125^{\circ}$ in the bath yielded $4.4 \mathrm{~g}$ of a colourless oil $\mathbf{( 7 9 . 5 \% )}$.

$$
\begin{array}{llllll}
\mathrm{C}_{17} \mathrm{H}_{18} \mathrm{O}_{2} \mathrm{~S}(286.4) & \text { Calc. } & \mathrm{C} 71.3 & \mathrm{H} 6.33 & \text { S } 11.2 \\
& \text { Found } & \text { " } 71.0 & \text { " } 6.26 & \text { " } 11.2
\end{array}
$$

Diphenylmethylthioglycolamide

$28.8 \mathrm{~g}$ of the ethyl ester was dissolved in $100 \mathrm{ml}$ of ethanol, and the solution was saturated, at a low temperature with ammonia gas. It was then heated in a sealed steel tube at $100^{\circ}$ for 16 hours. On cooling, $17.1 \mathrm{~g}$ of the amide separated. Recrystallization from ethanol gave white crystals with the m.p. 110-112.

$$
\begin{array}{lllll}
\mathrm{C}_{15} \mathrm{H}_{15} \mathrm{NOS}(257.3) & \text { Calc. } & \mathrm{N} & 5.45 & \mathrm{~S} 12.5 \\
& \text { Found } & \text { 5.42 } & \text { " } 12.3
\end{array}
$$

$\beta$-Diethylaminoethyl diphenylmethylthioglycolate

A mixture of $13.0 \mathrm{~g}$ of diphenylmethylthioglycolic acid, $8.6 \mathrm{~g}$ of $\beta$-diethylaminoethyl chloride hydrochloride, $13.5 \mathrm{~g}$ of potassium carbonate and $50 \mathrm{ml}$ of acetone was refluxed with stirring for 24 hours. The solution was filtered and acidified with a solution of dry hydrogen chloride in acetone. The precipitated hydrochloride amounted to $6.1 \mathrm{~g}$. After recrystallization from acetone it melted at $164-165^{\circ}$.

$$
\begin{array}{lllll}
\mathrm{C}_{21} \mathrm{H}_{27} \mathrm{NO}_{2} \mathrm{~S} \cdot \mathrm{HCl}(394.0) & \text { Calc. } & \text { Cl } 9.02 & \mathrm{~N} & 3.56 \\
& \text { Found } & 9.03 & & 3.56
\end{array}
$$

\section{SUMMARY}

The preparation of diphenylmethoxyacetic acid and a number of derivatives of this acid and diphenylmethylthioglycolic acid has been described.

\section{REFERENCES}

1. Holmberg, B. J. prakt. Chem. 141 (1934) 93.

2. Human, J. P. E., and Mills, J. A. Nature 158 (1946) 877.

3. Dahlbom, R., and Sjögren, B. Acta Chem. Scand. 1 (1947) 777.

4. Miescher, K., and Hoffmann, K. Helv. Chim. Acta 24 (1941) 458.

5. Slotta, K. H., and Behnisch, R. Ber. 68 (1935) 754.

Received June 29, 1948. 